\title{
Analisis Kualitas Pelayanan dengan Metode Fuzzy-SERVQUAL pada Dinas Kependudukan dan Pencatatan Sipil Kabupaten Gresik
}

\author{
Atikah Aghdhi Pratiwi \\ Departemen Teknik dan Sistem Industri, Fakultas Teknologi Industri dan Rekayasa Sistem, \\ Institut Teknologi Sepuluh Nopember, Jl. Raya ITS Sukolilo, Surabaya, 60111, Indonesia \\ atikah.aghdhi@gmail.com
}

\begin{abstract}
Abstrak
Salah satu pelayanan publik yang diatur dalam perundang-undangan adalah pelayanan di bidang administrasi kependudukan. Masyarakat sebagai pengguna jasa publik, menginginkan pelayanan yang berkualitas, namun keinginan tersebut seringkali tidak sesuai dengan harapan. Penelitian ini bertujuan untuk menganalisis kualitas pelayanan Dinas Kependudukan dan Pencatatan Sipil (DISPENDUKCAPIL) Kabupaten Gresik, khususnya pada bidang pelayanan pembuatan E-KTP. Metode yang digunakan dalam penelitian ini adalah SERVQUAL dengan melakukan analisis gap (kesenjangan) yang terjadi antara ekspektasi (harapan) dan persepsi (yang diterima) pelanggan terhadap kualitas pelayanan. Hasil penelitian menunjukkan bahwa terdapat 20 kriteria yang dinilai pelanggan memiliki gap negatif, artinya pelanggan masih belum puas terhadap pelayanan yang telah diberikan oleh divisi E-KTP DISPENDUKCAPIL Kabupaten Gresik selama ini. Selain itu, terdapat beberapa kriteria yang menjadi prioritas untuk ditingkatkan kualitas pelayanannya, yakni jaminan kualitas penyelesaian pelayanan, kenyamanan tempat pelayanan, penggunaan alat bantu pelayanan, dan kemudahan memperoleh akses pelayanan.
\end{abstract}

Kata kunci: pelayanan publik, kualitas pelayanan, service quality, pelayanan E-KTP

\section{Pendahuluan}

Sejak awal tahun 1990, peningkatan kualitas pelayanan telah menjadi perhatian, baik pada sektor publik maupun perusahaan swasta (Carr dan Littman, 1990; Pyon, dkk., 2009). Di samping itu, ada kecenderungan peningkatan ekspektasi pelanggan terhadap kualitas pelayanan yang diberikan oleh perusahaan. Hal ini didukung oleh perkembangan teknologi informasi yang berdampak pada keinginan pelanggan terhadap pelayanan yang lebih cepat, mudah, murah dan efisien (Yang, dkk., 2004).

Kualitas pelayanan tidak hanya diharapkan baik dan dinilai dari perusahaan komersil yang menjual produk atau jasa. Salah satu organisasi yang memerlukan perhatian terkait kualitas pelayanan adalah sektor publik atau instansi pemerintah. Pemimpin pada sektor publik perlu menerapkan standar dan peraturan pelayanan seperti yang diterapkan pada perusahaan swasta dengan lebih ketat. Penerapan ini terkait dengan pendekatan customer-focus yang bertujuan pada peningkatan kualitas sektor publik (Mwita, 2000).

Masyarakat/pelanggan sering menyatakan keluhan mengenai pelayanan yang diberikan oleh instansi pemerintahan. Keluhan yang diutarakan terkait dengan anggapan bahwa pelayanan yang diberikan masih kurang dan belum sesuai dengan standar. Sebelum memulai pengumpulan data, peneliti terlebih dahulu melakukan observasi untuk mengetahui kondisi eksisting mengenai kualitas pelayanan di DISPENDUKCAPIL Kabupaten Gresik dari persepsi pelanggan. Kesimpulan awal yang dapat ditarik adalah masyarakat masih belum puas pada pelayanan yang diberikan, utamanya pada pelayanan E-KTP. Beberapa keluhan yang diutarakan adalah mengenai pelayanan yang lama, tata letak ruangan yang kurang strategis dan kejelasan informasi yang diberikan oleh pegawai. Keterangan ini diperkuat oleh pernyataan Kepala Divisi Umum dan Kepegawaian yang menyatakan bahwa "pelayanan yang masih banyak dikeluhkan oleh masyarakat dan perlu ditingkatkan kualitasnya adalah pelayanan E-KTP". 
Pernyataan tersebut disimpulkan berdasarkan hasil survei kepuasan masyarakat (SKM) yang dilakukan oleh DISPENDUKCAPIL Gresik.

Salah satu metode pengukuran kualitas pelayanan yang kerap digunakan adalah service quality (SERVQUAL). SERVQUAL merupakan metode pengukuran kualitas yang mengukur besar gap antara persepsi dan ekspektasi pelanggan terhadap pelayanan yang diterima (Zoraghi, dkk., 2013). SERVQUAL memiliki 5 dimensi, yakni tangibles, reliability, responsiveness, assurance dan emphaty. Metode ini didefinisikan sebagai metode yang fokus pada usaha untuk memenuhi kebutuhan pelanggan dengan tujuan memenuhi harapan/ekspektasi pelanggan (Parasuraman, dkk., 1985).

Umumnya, SERVQUAL kerap kali digunakan sebagai metode tunggal dalam peningkatan kualitas pelayanan. Namun, SERVQUAL memiliki kecenderungan untuk mendapatkan data dengan tingkat subjektivitas cukup tinggi. Hal ini disebabkan, dalam pengukuran kualitas data yang digunakan murni dari pendapat pelanggan. Menurut Falch dan Silva (2018), fuzzy adalah salah satu metode yang efektif digunakan untuk mengurangi subjektivitas pada kriteria kualitatif yang digunakan pada sebuah masalah. Fuzzy juga merupakan metode yang dapat digunakan untuk menghitung kriteria yang kurang akurat, dan mengurangi subjektivitas. Oleh karena itu, dalam penelitian ini akan digunakan kombinasi fuzzy dan SERVQUAL untuk mencapai tujuan penelitian. Penelitian ini bertujuan untuk menganalisis kualitas pelayanan E-KTP dan memberikan saran perbaikan pada DISPENDUKCAPIL Kabupaten Gresik, sehingga diharapkan DISPENDUKCAPIL Kabupaten Gresik dapat memperbaiki kualitas pelayanannya.

\section{Metode Penelitian}

Secara umum, penelitian ini terbagi menjadi 5 tahap: perancangan blueprint eksisting, pengumpulan data atribut, uji validitas dan reliabilitas, perhitungan data berupa fuzzifikasi persepsiekspektasi pelanggan dan perhitungan SERVQUAL per kriteria, per dimensi, dan keseluruhan. Tahap akhir yang dilaksanakan adalah rekomendasi blueprint perbaikan. Pada tahap pengumpulan data dan analisis rekomendasi, terdapat beberapa metode yang digunakan, yakni survey, pengumpulan kuesioner dan wawancara.

\section{a. Perancangan Blueprint Eksisting}

Blueprint jasa menggambarkan sifat dan karakteristik operasional suatu jasa. Pada tahap ini akan digambarkan proses layanan E-KTP eksisting yang dilakukan oleh DISPENDUKCAPIL Kabupaten Gresik. Tahap ini penting dalam membantu menganalisis konsep dari system, struktur dasar dan organisasi jasa untuk kemudian dikembangkan dan dievaluasi.

\section{b. Pengumpulan Data Atribut}

Tahap ini terdiri dari beberapa sub-tahap. Dimulai dengan perancangan atribut kuesioner SERVQUAL yang memiliki 5 dimensi sesuai yang dikemukakan oleh Parasuraman, dkk., (1985) dengan melakukan observasi pada sistem pelayanan eksisting. Skala pengukuran yang digunakan untuk penelitian ini adalah skala likert dengan 5 jenjang kriteria untuk mengukur masing-masing dimensi SERVQUAL.

Populasi dari penelitian ini merupakan masyarakat/pelanggan yang sedang atau telah menggunakan layanan E-KTP pada DISPENDUKCAPIL Kabupaten Gresik. Teknik sampling yang digunakan dalam penelitian ini adalah non-probability sampling dengan metode sampling insidental. Menurut Sugiyono (2017), sampling insidental adalah teknik penentuan sampel berdasarkan kebetulan, yaitu siapa saja yang secara kebetulan insidental bertemu dengan peneliti agar dapat digunakan sebagai sampel. Kriteria sampel yang digunakan adalah: orang yang sedang menggunakan layanan pembuatan E-KTP pada DISPENDUKCAPIL Kabupaten Gresik. Dalam penelitian ini dilakukan tujuh hari penyebaran kuesioner, dan diperoleh 105 responden. 


\section{c. Uji Validitas dan Reliabilitas}

Uji validitas digunakan untuk mengukur valid atau tidaknya sebuah kuesioner (Ghozali, 2016). Suatu kuesioner dikatakan valid apabila pertanyaan pada kuesioner mampu menjelaskan sesuatu yang akan diukur oleh kuesioner tersebut. Dalam sebuah penelitian, uji validitas menggunakan teknik pengujian Pearson dengan taraf kepercayaan 95\% dan tingkat ketelitian $(\alpha)$ sebesar 0,05 . Nilai yang digunakan dalam penelitian ini adalah jika nilai koefisien yang diperoleh kurang dari $(<) \alpha$, berarti pertanyaan tersebut valid dan jika lebih besar $(>) \alpha$ berarti pertanyaan tersebut dianggap tidak valid.

Uji validitas dilakukan dengan menyebarkan kuesioner sebanyak 30 responden untuk menguji validitas atribut atau pertanyaan yang terdapat pada kuesioner. Setelah hasil kuesioner didapatkan, selanjutnya dilakukan perhitungan dengan menggunakan software SPSS.

Uji reliabilitas dilakukan terhadap kuesioner dengan tujuan untuk mengetahui konsistensi dari alat ukur dalam mengukur gejala yang sama dalam waktu yang berbeda (Umar, 2002). Uji reliabilitas untuk penelitian ini menggunakan teknik pengujian alpha cronbach's dengan taraf kepercayaan $95 \%$ dan tingkat ketelitian $(\alpha)$ sebesar 0,05 . Uji keandalan dilakukan pada kuesioner dengan menggunakan reliability analysis pada software SPSS, nilai yang digunakan dalam penelitian ini jika nilai koefisien yang diperoleh lebih dari (>) 0,60 berarti kuesioner dinyatakan reliable dan jika kurang dari $(<)$ 0,60 dinyatakan tidak reliable.

\section{d. Perhitungan Data Fuzzifikasi dan SERVQUAL}

Perhitungan Fuzzifikasi dilakukan dengan mengintegrasikan antara metode fuzzy dan SERVQUAL untuk menghilangkan subjektivitas pada data yang dimiliki oleh metode SERVQUAL yang dilakukan dengan membentuk membership function dengan triangular fuzzy number sebagai pengukuran persepsi dan ekspektasi pelanggan, perhitungan nilai SERVQUAL terbobot dan penilaian tingkat kepentingan suatu kriteria. Tahapan dalam melakukan fuzzifikasi SERVQUAL adalah sebagai berikut:

1) Menentukan skor pada kategori yang akan digunakan dalam penilaian responden dengan menggunakan nilai fuzzy set.

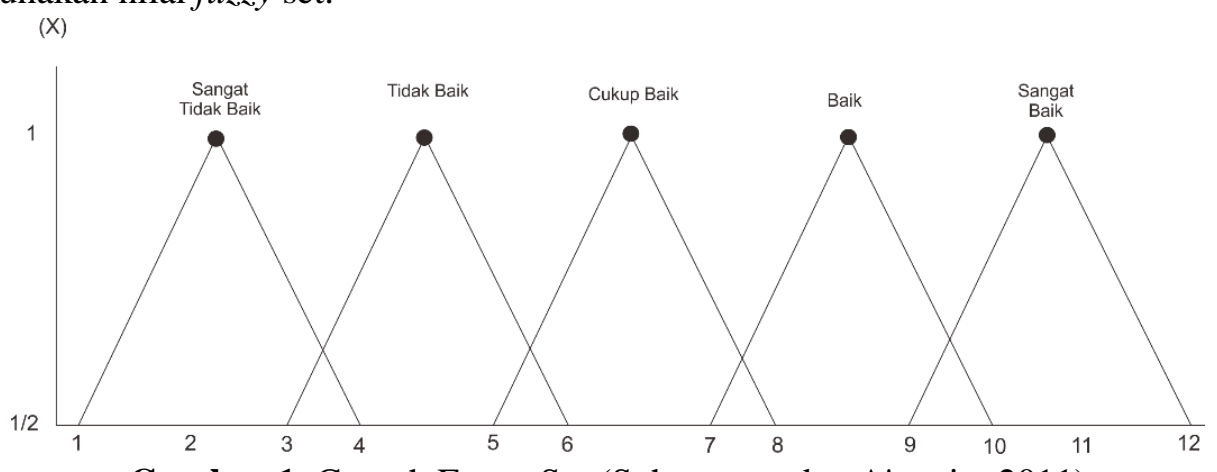

Gambar 1. Contoh Fuzzy Set (Suharyanta dan A'yunin, 2011)

Gambar 1 menunjukkan bahwa nilai yang digunakan dalam penentuan bobot (skor) yang digunakan untuk mengetahui tingkat kualitas pelayanan dari perhitungan fuzzifikasi adalah sebagai berikut:

a. Kategori 1 = sangat tidak baik dengan skor 1,2,3,4 (meliputi jawaban kuesioner persepsi/harapan yaitu sangat tidak setuju/sangat tidak diharapkan).

b. Kategori 2 = tidak baik dengan skor 3,4,5,6 (meliputi jawaban kuesioner persepsi/harapan yaitu tidak setuju/tidak diharapkan).

c. Kategori 3 = cukup baik dengan skor 5,6,7,8 (meliputi jawaban kuesioner persepsi/harapan yaitu cukup setuju/cukup diharapkan).

d. Kategori 4 = baik dengan skor 7,8,9,10 (meliputi jawaban kuesioner persepsi/harapan yaitu setuju/diharapkan).

e. Kategori $5=$ sangat baik dengan skor 9,10,11,12 (meliputi jawaban kuesioner persepi/harapan yaitu sangat setuju/sangat diharapkan). 
2) Melakukan fuzzifikasi pada kuesioner yang telah didapat dan dilakukan perhitungan fuzzifikasi pada data kuesioner persepsi dan harapan pelanggan. Perhitungan dilakukan dengan menentukan batas bawah hingga batas atas nilai perkepentingan. Cara perhitungan batas atas hingga bawah adalah sebagai berikut:

$$
\begin{aligned}
& \text { Batas Bawah }(c)=\frac{b i 1 * n 1+b i 1 * n 2+b i 2 * n 3+\cdots+b i(k-1) * n k}{n 1+n 2+n 3+\cdots+n k} \\
& \text { Batas Tengah }(a)=\frac{b i 1 * n 1+b i 2 * n 2+b i 3 * n 3+\cdots+b i k * n k}{n 1+n 2+n 3+\cdots+n k} \\
& \text { Batas Atas }(b)=\frac{b i 2 * n 1+b i 3 * n 2+\cdots+b i k * n i(k-1)+b i k * n k}{n 1+n 2+n 3+\cdots+n(k-1)+n k}
\end{aligned}
$$

Keterangan rumus:

$b_{i}=$ nilai batas bawah (c), rata-rata skor (a) dan batas atas (b) dari skor masing-masing kategori yang didapatkan masing- masing atribut pada kuesioner.

$n=$ jumlah responden per kriteria dalam kuesioner

$i=$ kriteria $(1,2,3, \ldots k)$

3) Setelah dilakukan metode fuzzifikasi selanjutnya defuzzifikasi yaitu menggambarkan nilai tunggal yang representatif dengan kriteria yang dimaksud menggunakan formulasi sebagai berikut:

Defuzzifikasi $=\frac{a+b+c}{3}$

$$
\begin{aligned}
& \text { Keterangan rumus: } \\
& \begin{array}{l}
a= \\
b=\text { nilai dari batas tengah (a) pada perhitungan fuzzifikasi } \\
b=\text { nilai dari batas atas (b) pada perhitungan fuzzifikasi } \\
c=\text { nilai dari batas bawah (c) pada perhitungan fuzzifikasi }
\end{array}
\end{aligned}
$$

Perhitungan SERVQUAL per kriteria akan menunjukkan sejauh mana pihak DISPENDUKCAPIL Kabupaten Gresik memberikan pelayanan E-KTP yang sesuai dengan ekspektasi pelanggan. Perhitungan gap per kriteria akan memberikan tingkat kepentingan pada indikator kriteria dalam meningkatkan kualitas pelayanan. Perhitungan SERVQUAL per dimensi akan menunjukkan selisih dari persepsi dan ekspektasi pelanggan pada pelayanan yang telah diberikan DISPENDUKCAPIL Kabupaten Gresik. Perhitungan dilakukan pada tingkat kepentingan kelima dimensi SERVQUAL dalam peningkatan kualitas pelayanan DISPENDUKCAPIL Kabupaten Gresik. Perhitungan SERVQUAL keseluruhan akan menunjukkan selisih tingkat persepsi dan harapan yang diinginkan pelanggan melalui peran gap keseluruhan yang akan memberikan informasi seberapa jauh kriteria tersebut dalam meningkatkan kualitas pelayanan.

\section{e. Rekomendasi Blueprint Jasa Perbaikan}

Rekomendasi blueprint jasa akan diberikan kepada DISPENDUKCAPIL Kabupaten Gresik untuk perbaikan blueprint awal yang sesuai dengan kondisi eksisting saat ini, berdasarkan hasil perhitungan yang telah dilakukan pada tahap sebelumnya. 


\section{Hasil dan Pembahasan}

\section{a. Perancangan Blueprint Eksisting}

Blueprint merupakan sebuah diagram yang digunakan untuk menggambarkan alur dan karakteristik dalam sebuah pelayanan. Berikut adalah hasil perancangan blueprint pada kondisi eksisting pelayanan E-KTP di DISPENDUKCAPIL Kabupaten Gresik.

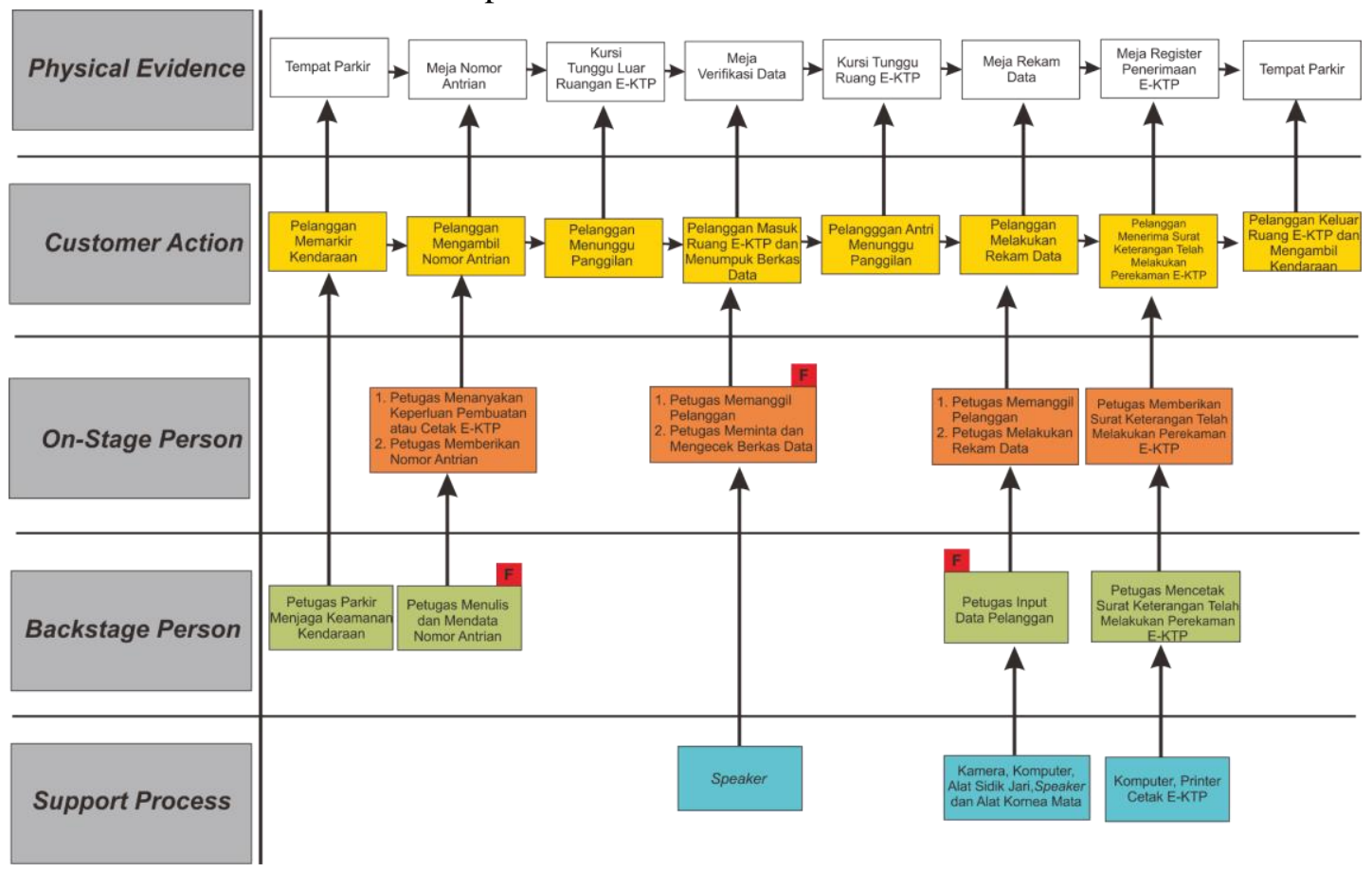

Gambar 2. Blueprint Eksisting Layanan Pembuatan Awal E-KTP

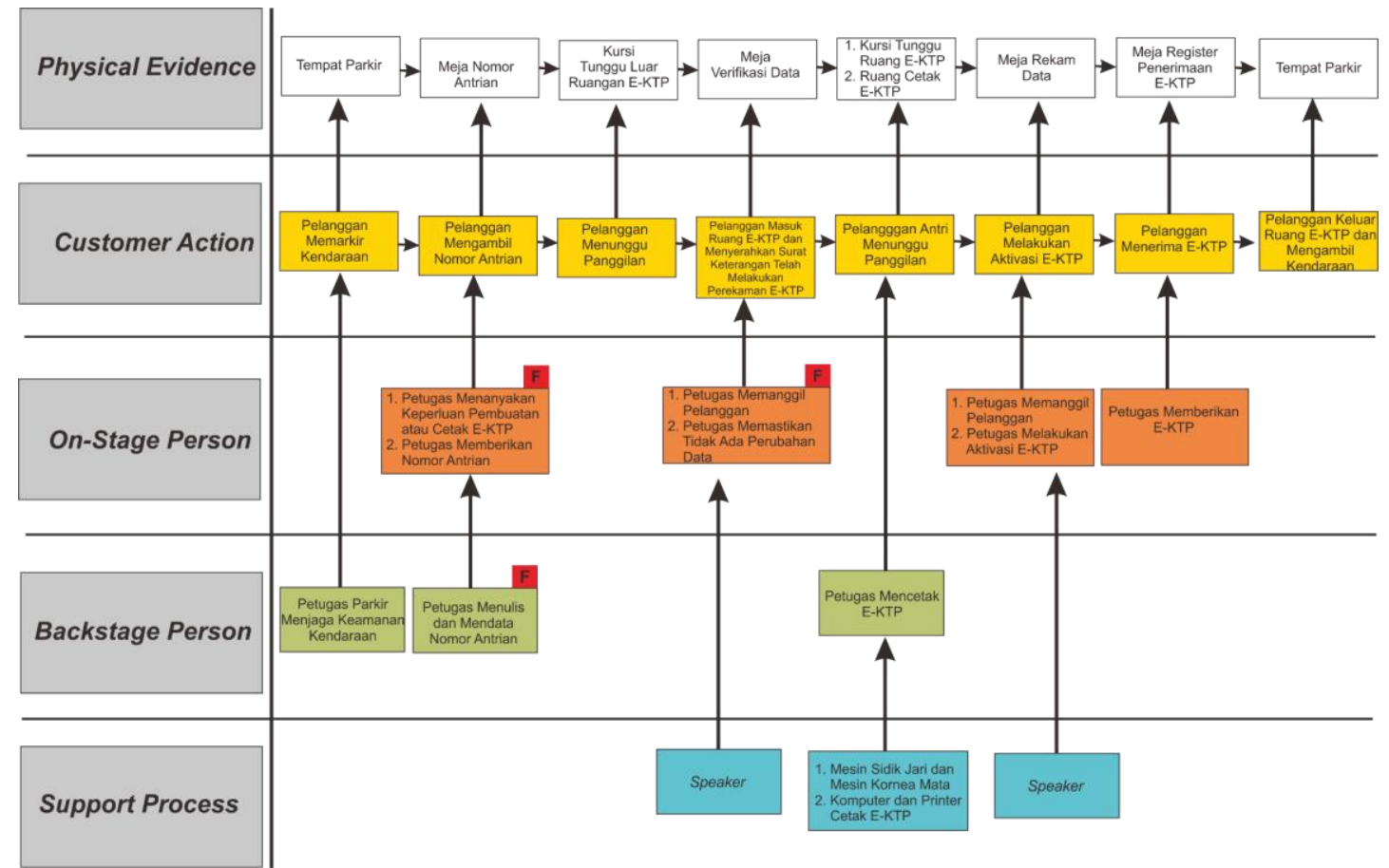

Gambar 3. Blueprint Eksisting Layanan Cetak E-KTP

Dalam layanan E-KTP terdapat dua proses yaitu proses pembuatan awal E-KTP (Gambar 2) dan pengambilan E- KTP (Gambar 3) yang mana tidak berlangsung dalam satu hari sehingga terdapat dua blueprint jasa yang diterapkan pada DISPENDUKCAPIL Kabupaten Gresik untuk layanan E-KTP, yang dibagi menjadi lima dimensi sebagai berikut: 
1. Physical evidence merupakan fasilitas fisik yang diterima dan atau dirasakan oleh masyarakat ketika menggunakan layanan DISPENDUKCAPIL Kabupaten Gresik diantaranya adalah tempat parkir, ruang layanan E-KTP, meja nomor antrian, kursi tunggu, meja verifikasi data, ruang cetak E-KTP, meja rekam data, meja register penerimaan E-KTP.

2. Customer action merupakan seluruh aktivitas yang dilakukan pihak penyedia layanan dan melibatkan pelanggan dalam proses pemberian jasa. Customer action yang terjadi dalam blueprint DISPENDUKCAPIL Kabupaten Gresik adalah pelanggan memarkir kendaraan, pelanggan mengambil nomor antrian, pelanggan menunggu panggilan, pelanggan masuk ruang E-KTP dan menumpuk berkas, pelanggan melakukan rekam data, pelanggan menerima surat keterangan telah melakukan perekaman E-KTP, pelanggan menyerahkan surat keterangan telah melakukan perekaman E-KTP, pelanggan melakukan aktivasi E-KTP, dan pelanggan menerima E-KTP.

3. Onstage contact-employee action adalah aktivitas front liner atau pegawai yang berhubungan langsung dengan pelanggan sehingga aktivitas ini dianggap paling penting untuk penilaian suatu jasa. Aktivitas onstage contact-employee action dalam blueprint DISPENDUKCAPIL Kabupaten Gresik adalah petugas menanyakan keperluan pelanggan membuat atau mencetak E-KTP, petugas memberikan nomor antrian, petugas memanggil pelanggan dan mengecek berkas pelanggan, petugas memastikan berkas tidak ada perubahan, petugas memanggil pelanggan dan melakukan rekam data, petugas memberikan surat keterangan telah melakukan rekam E-KTP, petugas memanggil pelanggan dan melakukan aktivasi, dan petugas memberikan E-KTP.

4. Backstage contact-employee action adalah aktivitas yang tidak melibatkan pelanggan secara langsung. Aktivitas backstage contact-employee action dalam blueprint DISPENDUKCAPIL Kabupaten Gresik adalah petugas parkir menjaga keamanan kendaraan pelanggan, petugas menulis dan mendata nomor antrian, petugas menginput data pelanggan, petugas mencetak surat keterangan telah melakukan perekaman E-KTP, dan petugas memberikan E-KTP kepada pelanggan.

5. Support process adalah aktivitas pendukung proses penyampaian jasa pihak penyedia layanan kepada para pelanggan. Support process dalam blueprint DISPENDUKCAPIL Kabupaten Gresik adalah kamera, komputer, printer, mesin cetak E-KTP, alat sidik jari, alat kornea mata, dan speaker.

Terdapat beberapa proses/aktivitas dalam blueprint yang diberi tanda "F" (possibility failed) yang menunjukkan bahwa aktivitas tersebut rentan terjadi kesalahan akibat human error ataupun machine error sehingga perlu untuk ditingkatkan dalam hal controlling ataupun machine maintenance.

\section{b. Perhitungan Data Fuzzifikasi dan SERVQUAL}

Kuesioner yang dirancang dan dibagikan pada responden memiliki 26 pertanyaan, dengan 7 pertanyaan pada dimensi tangible, 5 pertanyaan pada dimensi reliability, 5 pertanyaan dalam dimensi responsiveness, 4 pertanyaan pada dimensi assurance dan 5 pertanyaan pada dimensi empathy.

Tabel 1. Daftar Pertanyaan

\begin{tabular}{cl}
\hline No. & \multicolumn{1}{c}{ PERTANYAAN } \\
\hline & \multicolumn{1}{c}{ TANGIBLE (BUKTI FISIK) } \\
1. & Kenyamanan tempat melakukan pelayanan \\
2. & Kebersihan tempat pelayanan \\
3. & Kemudahan memperoleh akses layanan \\
4. & Penampilan petugas/aparatur dalam melayani pelanggan \\
5. & Tempat parkir yang luas \\
6. & Penggunaan media alat bantu pelayanan (misalnya : mesin nomor antrian, speaker panggilan pelanggan) \\
7. & Kejelasan petunjuk arah ruang pelayanan \\
\hline
\end{tabular}


Tabel 1. Daftar Pertanyaan (lanjutan)

\begin{tabular}{ll}
\hline No. & \multicolumn{1}{c}{ PERTANYAAN } \\
\hline & \multicolumn{1}{c}{ TANGIBLE (BUKTI FISIK) } \\
1. & Kenyamanan tempat melakukan pelayanan \\
2. & Kebersihan tempat pelayanan \\
3. & Kemudahan memperoleh akses layanan \\
4. & Penampilan petugas/aparatur dalam melayani pelanggan \\
5. & Tempat parkir yang luas \\
6. & Penggunaan media alat bantu pelayanan (misalnya : mesin nomor antrian, speaker panggilan pelanggan) \\
7. & Kejelasan petunjuk arah ruang pelayanan \\
\hline
\end{tabular}

\section{RELIABILITY (KEANDALAN)}

8. Kemampuan petugas menyampaikan pelayanan secara jelas

9. Keahlian petugas dalam memberikan pelayanan

10. Ketepatan waktu pelayanan dan kedisiplinan petugas dalam melakukan pelayanan

11. Tanggungjawab petugas dalam memberikan pelayanan

12. Kecermatan petugas dalam melayani pelanggan

\section{RESPONSIVENESS (KETANGGAPAN)}

13. Petugas merespon setiap pelanggan/pemohon yang ingin mendapatkan pelayanan

14. Petugas melakukan pelayanan dengan cepat dan tepat

15. Petugas melakukan pelayanan dengan inisiatif dan cermat

16. Petugas membantu pelanggan memperoleh informasi dan merespon

16. keluhan pelanggan

17. Petugas dapat mengantisipasi dan memahami kebutuhan khusus pelanggan

\section{ASSURANCE (JAMINAN)}

18. Jaminan kemudahan prosedur pelayanan

19. Jaminan kemudahan persyaratan pelayanan

20. Jaminan kepastian biaya dalam pelayanan

21. Jaminan kepastian waktu penyelesaian pelayanan

\section{EMPATHY (EMPATI)}

22. Petugas melayani dengan sikap ramah

23. Petugas melayani dengan sikap sopan santun

24. Petugas melayani dengan tidak diskriminatif (membeda-bedakan)

25. Petugas melayani dan menghargai setiap pelanggan

26. Petugas mendahulukan kepentingan pemohon/pelanggan

Sebagaia uji pendahuluan, kuesioner terlebih dahuu disebarkan pada 30 responden, dan kemudian dilakukan uji validitas dan reliabilitas. Pada uji yang dilakukan, seluruh pertanyaan dinyatakan valid dan reliable sehingga penelitian dapat dilanjutkan dengan menyebarkan kuesioner pada 105 responden yang ditemui dan sesuai dengan kriteria sampel. Berikut merupakan hasil perhitungan fuzzifikasi kuesioner persepsi dan ekspektasi yang telah dikumpulkan dari seluruh responden.

Tabel 2. Hasil Fuzzifikasi Persepsi

\begin{tabular}{|c|c|c|c|c|c|c|}
\hline \multirow{2}{*}{ No. } & \multirow{2}{*}{ Kriteria } & \multicolumn{3}{|c|}{ TFN } & \multirow{2}{*}{ Defuzzifikasi } & \multirow{2}{*}{ Rank } \\
\hline & & $\mathbf{a}$ & b & c & & \\
\hline 1. & Kenyamanan tempat melakukan pelayanan & 307,2 & 374,1 & 440,9714 & 374,1 & 19 \\
\hline 2. & Kebersihan tempat pelayanan & 530,3 & 664,1 & 797,8286 & 664,1 & 2 \\
\hline 3. & Kemudahan memperoleh akses layanan & 253,7 & 311,7 & 369,6571 & 311,7 & 24 \\
\hline 4. & $\begin{array}{l}\text { Penampilan petugas/aparatur dalam melayani } \\
\text { pelanggan }\end{array}$ & 473,1 & 627,7 & 782,2286 & 627,7 & 3 \\
\hline 5. & Tempat parkir yang luas & 307,2 & 374,1 & 440,9714 & 374,1 & 20 \\
\hline 6. & $\begin{array}{l}\text { Penggunaan media alat bantu pelayanan } \\
\text { (misalnya: mesin nomor antrian, speaker } \\
\text { panggilan pelanggan) }\end{array}$ & 319,9 & 391,3 & 462,6286 & 391,3 & 17 \\
\hline 7. & Kejelasan petunjuk arah ruang pelayanan & 271,2 & 338,1 & 404,9 & 338,1 & 23 \\
\hline
\end{tabular}


Tabel 2. Hasil Fuzzifikasi Persepsi (lanjutan)

\begin{tabular}{|c|c|c|c|c|c|c|}
\hline \multirow{2}{*}{ No. } & \multirow{2}{*}{ Kriteria } & \multicolumn{3}{|c|}{ TFN } & \multirow{2}{*}{ Defuzzifikasi } & \multirow{2}{*}{ Rank } \\
\hline & & $\underline{\mathbf{a}}$ & b & c & & \\
\hline 8. & $\begin{array}{l}\text { Kemampuan petugas menyampaikan pelayanan } \\
\text { secara jelas }\end{array}$ & 294,3 & 359,7 & 425 & 359,7 & 22 \\
\hline 9. & Keahlian petugas dalam memberikan pelayanan & 334,3 & 416,1 & 497,8 & 416,1 & 14 \\
\hline 10. & $\begin{array}{l}\text { Ketepatan waktu pelayanan dan kedisiplinan petugas } \\
\text { dalam melakukan pelayanan }\end{array}$ & 522,2 & 675,3 & 828,3 & 675,3 & 1 \\
\hline 11. & $\begin{array}{l}\text { Tanggungjawab petugas dalam memberikan } \\
\text { pelayanan }\end{array}$ & 330,3 & 412,1 & 493,8 & 412,1 & 15 \\
\hline 12. & Kecermatan petugas dalam melayani pelanggan & 307,9 & 379,3 & 450,6 & 379,3 & 18 \\
\hline 13. & $\begin{array}{l}\text { Petugas merespon setiap pelanggan/pemohon yang } \\
\text { ingin mendapatkan pelayanan }\end{array}$ & 366,3 & 448,1 & 529,8 & 448,1 & 7 \\
\hline 14. & Petugas melakukan pelayanan dengan cepat dan tepat & 349,6 & 426,9 & 504,1 & 426,9 & 9 \\
\hline 15. & $\begin{array}{l}\text { Petugas melakukan pelayanan dengan inisiatif dan } \\
\text { cermat }\end{array}$ & 455,4 & 587,7 & 719,9 & 587,7 & 4 \\
\hline 16. & $\begin{array}{l}\text { Petugas membantu pelanggan memperoleh informasi } \\
\text { dan merespon keluhan pelanggan }\end{array}$ & 180,7 & 220,9 & 261 & 220,9 & 26 \\
\hline 17. & $\begin{array}{l}\text { Petugas dapat mengantisipasi dan memahami } \\
\text { kebutuhan khusus pelanggan }\end{array}$ & 366,3 & 448,1 & 529,8 & 448,1 & 8 \\
\hline 18. & Jaminan kemudahan prosedur pelayanan & 423,7 & 533,7 & 643,6 & 533,7 & 6 \\
\hline 19. & Jaminan kemudahan persyaratan pelayanan & 349,6 & 426,9 & 504,1 & 426,9 & 10 \\
\hline 20. & Jaminan kepastian biaya dalam pelayanan & 302,3 & 367,7 & 433,0 & 367,7 & 21 \\
\hline 21. & Jaminan kepastian waktu penyelesaian pelayanan & 210,4 & 256,5 & 302,5 & 256,5 & 25 \\
\hline 22. & Petugas melayani dengan sikap ramah & 347,6 & 424,9 & 502,1 & 424,9 & 12 \\
\hline 23. & Petugas melayani dengan sikap sopan santun & 349,6 & 426,9 & 504,1 & 426,9 & 11 \\
\hline 24. & $\begin{array}{l}\text { Petugas melayani dengan tidak diskriminatif } \\
\text { (membeda-bedakan) }\end{array}$ & 344,7 & 420,5 & 496,2 & 420,5 & 13 \\
\hline 25. & Petugas melayani dan menghargai setiap pelanggan & 455,4 & 587,7 & 719,9 & 587,7 & 5 \\
\hline 26. & $\begin{array}{l}\text { Petugas mendahulukan kepentingan } \\
\text { pemohon/pelanggan }\end{array}$ & 330,8 & 403,7 & 476,5 & 403,7 & 16 \\
\hline
\end{tabular}

Keterangan:

TFN = Triangular Fuzzy Number

$\mathrm{a} \quad=$ batas tengah

$\mathrm{b}=$ batas atas

$\mathrm{c} \quad=$ batas bawah

Dari Tabel 2. dapat diketahui bahwa nilai persepsi (yang dirasakan) pelanggan terhadap layanan EKTP pada DISPENDUKCAPIL Kabupaten Gresik dari masing-masing kriteria, kriteria "ketepatan waktu pelayanan dan kedisiplinan petugas dalam melakukan pelayanan" memiliki nilai tertinggi yaitu sebesar 675,3 dari semua kriteria. Hal ini dapat menunjukkan bahwa ketepatan waktu pelayanan dan kedisiplinan petugas dalam melakukan pelayanan dilaksanakan dengan baik, sehingga masyarakat pengguna layanan E-KTP pada DISPENDUKCAPIL Kabupaten Gresik merasa puas. Tingginya nilai pada kriteria tersebut membuktikan bahwa selama ini petugas layanan E-KTP DISPENDUKCAPIL Kabupaten Gresik telah mendapatkan kepercayaan masyarakat akan ketepatan waktu pelayanan dan kedisplinan dalam bekerja.

Sedangkan untuk nilai kriteria paling rendah yaitu "Petugas membantu pelanggan memperoleh informasi dan merespon keluhan pelanggan" dengan nilai sebesar 220,9. Hal ini dapat menunjukkan bahwa petugas membantu pelanggan memperoleh informasi dan merespon keluhan pelanggan dilakukan dengan kurang baik, sehingga masyarakat pengguna layanan E-KTP merasa tidak puas karena masyarakat membutuhkan petugas dalam memberikan informasi dan merespon keluhan untuk dapat menyelesaikan permasalahan yang ada. Oleh karena itu, dibutuhkan perbaikan salah satunya dengan meningkatkan ketanggapan dan kesadaran (awareness) petugas kepada pelanggan karena DISPENDUKCAPIL Kabupaten Gresik merupakan pelayanan publik yang berhadapan langsung 
dengan masyarakat, sehingga sikap dan ketanggapan petugas dalam melakukan pelayanan sangat penting dalam penilaian kualitas pelayanan yang diberikan.

Tabel 3. Hasil Fuzzifikasi Ekspektasi

\begin{tabular}{|c|c|c|c|c|c|c|}
\hline \multirow[t]{2}{*}{ No. } & \multirow[t]{2}{*}{ Kriteria } & \multicolumn{3}{|c|}{ TFN } & \multirow[t]{2}{*}{ Defuzzifikasi } & \multirow[t]{2}{*}{ Rank } \\
\hline & & $\mathbf{a}$ & b & c & & \\
\hline 1. & Kenyamanan tempat melakukan pelayanan & 565,5 & 709,7 & 854 & 709,7 & 2 \\
\hline 2. & Kebersihan tempat pelayanan & 299,3 & 365,2 & 431,1 & 365,2 & 22 \\
\hline 3. & Kemudahan memperoleh akses layanan & 446,3 & 599,3 & 752,4 & 599,3 & 16 \\
\hline 4. & $\begin{array}{l}\text { Penampilan petugas/aparatur dalam melayani } \\
\text { pelanggan }\end{array}$ & 175,6 & 214,6 & 253,5 & 214,6 & 25 \\
\hline 5. & Tempat parkir yang luas & 537,1 & 674 & 810,8 & 674 & 9 \\
\hline 6. & $\begin{array}{l}\text { Penggunaan media alat bantu pelayanan (misalnya: } \\
\text { mesin nomor antrian, speaker panggilan pelanggan) }\end{array}$ & 547,4 & 684,3 & 821,2 & 684,3 & 6 \\
\hline 7. & Kejelasan petunjuk arah ruang pelayanan & 484,8 & 621,6 & 758,4 & 621,6 & 13 \\
\hline 8. & $\begin{array}{l}\text { Kemampuan petugas menyampaikan pelayanan } \\
\text { secara jelas }\end{array}$ & 474,8 & 601,3 & 727,8 & 601,3 & 15 \\
\hline 9. & Keahlian petugas dalam memberikan pelayanan & 519,9 & 658,2 & 796,6 & 658,2 & 11 \\
\hline 10. & $\begin{array}{l}\text { Ketepatan waktu pelayanan dan kedisiplinan petugas } \\
\text { dalam melakukan pelayanan }\end{array}$ & 227,4 & 278,3 & 329,2 & 278,3 & 23 \\
\hline 11. & $\begin{array}{l}\text { Tanggungjawab petugas dalam memberikan } \\
\text { pelayanan }\end{array}$ & 519,9 & 658,2 & 796,6 & 658,2 & 12 \\
\hline 12. & Kecermatan petugas dalam melayani pelanggan & 473 & 596,5 & 720 & 596,5 & 17 \\
\hline 13. & $\begin{array}{l}\text { Petugas merespon setiap pelanggan/pemohon yang } \\
\text { ingin mendapatkan pelayanan }\end{array}$ & 386 & 475,6 & 565,3 & 475,6 & 21 \\
\hline 14. & Petugas melakukan pelayanan dengan cepat dan tepat & 557,1 & 697 & 836,8 & 697 & 3 \\
\hline 15. & $\begin{array}{l}\text { Petugas melakukan pelayanan dengan inisiatif dan } \\
\text { cermat }\end{array}$ & 427,9 & 535,2 & 642,5 & 535,2 & 19 \\
\hline 16. & $\begin{array}{l}\text { Petugas membantu pelanggan memperoleh informasi } \\
\text { dan merespon keluhan pelanggan }\end{array}$ & 396,9 & 499,7 & 602,6 & 499,7 & 20 \\
\hline 17. & $\begin{array}{l}\text { Petugas dapat mengantisipasi dan memahami } \\
\text { kebutuhan khusus pelanggan }\end{array}$ & 578,4 & 724,1 & 869,9 & 724,1 & 1 \\
\hline 18. & Jaminan kemudahan prosedur pelayanan & 185,5 & 227,4 & 269 & 227,4 & 24 \\
\hline 19. & Jaminan kemudahan persyaratan pelayanan & 107,8 & 131, & 155,7 & 131,7 & 26 \\
\hline 20. & Jaminan kepastian biaya dalam pelayanan & 428,7 & 575,8 & 722,9 & 575,8 & 18 \\
\hline 21. & Jaminan kepastian waktu penyelesaian pelayanan & 557,1 & 697 & 836,8 & 697 & 4 \\
\hline 22. & Petugas melayani dengan sikap ramah & 548,4 & 691,1 & 833,9 & 691,1 & 5 \\
\hline 23. & Petugas melayani dengan sikap sopan santun & 548,6 & 684 & 819,5 & 684 & 7 \\
\hline 24. & $\begin{array}{l}\text { Petugas melayani dengan tidak diskriminatif } \\
\text { (membeda-bedakan) }\end{array}$ & 550 & 684 & 818 & 684 & 8 \\
\hline 25. & Petugas melayani dan menghargai setiap pelanggan & 495,3 & 610,2 & 725,1 & 610,2 & 14 \\
\hline 26. & $\begin{array}{l}\text { Petugas mendahulukan kepentingan } \\
\text { pemohon/pelanggan }\end{array}$ & 523,4 & 664,6 & 805,9 & 664,6 & 10 \\
\hline & Keterangan: & & & & & \\
\hline & $\mathrm{FN}=$ Triangular Fuzzy Number & & & & & \\
\hline & $=$ batas tengah & & & & & \\
\hline 0 & $=$ batas atas & & & & & \\
\hline & $=$ batas bawah & & & & & \\
\hline
\end{tabular}

Dari Tabel 3 dapat diketahui bahwa nilai ekspektasi (yang diharapkan) pelanggan terhadap pelayanan DSIPENDUKCAPIL Kabupaten Gresik, kriteria "Petugas dapat mengantisipasi dan memahami kebutuhan khusus pelanggan" memiliki nilai tertinggi yaitu sebesar 724,18 dari semua kriteria. Hal ini dapat menunjukkan bahwa Petugas dapat mengantisipasi dan memahami kebutuhan khusus pelanggan sangat penting bagi masyarakat pengguna layanan E-KTP pada DISPENDUKCAPIL Kabupaten Gresik sehingga perlu untuk diperhatikan dalam penerapan untuk dapat lebih memahami kebutuhan khusus pelanggan seperti misalnya kebutuhan E-KTP yang dijadikan sebuah persyaratan yang mendesak. 
Sedangkan untuk nilai kriteria paling rendah yaitu "Jaminan kemudahan persyaratan pelayanan" dengan nilai sebesar 131,7717. Hal ini dapat menunjukkan bahwa jaminan kemudahan persyaratan pelayanan bukan menjadi hal penting untuk menilai kualitas pelayanan sehingga tidak menjadi prioritas DISPENDUKCAPIL Kabupaten Gresik untuk melakukan perbaikan. Karena persyaratan E-KTP merupakan ketentuan peraturan dari pemerintah yang telah ditetapkan, akan tetapi apabila persyaratan pelayanan diperbaiki untuk mempermudah masyarakat dalam mengurus E-KTP dan memenuhi harapan pelanggan maka kriteria ini akan meningkatkan nilai pada dimensi assurance (jaminan). Tabel 4 dibawah menunjukkan hasil perhitungan gap SERVQUAL.

Tabel 4. Hasil Perhitungan Gap SERVQUAL

\begin{tabular}{|c|c|c|c|c|c|}
\hline No. & Kriteria & Persepsi & Harapan & Gap & Rank \\
\hline 1. & Kenyamanan tempat melakukan pelayanan & 374,1 & 709,7 & $-335,6$ & 2 \\
\hline 2. & Kebersihan tempat pelayanan & 664,1 & 365,2 & 298,8 & 23 \\
\hline 3. & Kemudahan memperoleh akses layanan & 311,7 & $\mathbf{5 9 9 , 3}$ & $-287,6$ & 5 \\
\hline 4. & Penampilan petugas/aparatur dalam melayani pelanggan & 627,7 & 214,6 & 413 & 26 \\
\hline 5. & Tempat parkir yang luas & 374,1 & 674 & $-299,9$ & 3 \\
\hline 6. & $\begin{array}{l}\text { Penggunaan media alat bantu pelayanan (misalnya : } \\
\text { mesin nomor antrian, speaker panggilan pelanggan) }\end{array}$ & 391,3 & 684,3 & -293 & 4 \\
\hline 7. & Kejelasan petunjuk arah ruang pelayanan & 338,1 & 621,6 & $-283,5$ & 6 \\
\hline 8. & Kemampuan petugas menyampaikan pelayanan secara jelas & 359,7 & 601,3 & $-241,6$ & 16 \\
\hline 9. & Keahlian petugas dalam memberikan pelayanan & 416,1 & 658,2 & $-242,1$ & 15 \\
\hline 10. & $\begin{array}{l}\text { Ketepatan waktu pelayanan dan kedisiplinan petugas dalam } \\
\text { melakukan pelayanan }\end{array}$ & 675,3 & 278,3 & 396,9 & 25 \\
\hline 11. & Tanggungjawab petugas dalam memberikan pelayanan & 412,1 & 658,2 & $-246,1$ & 14 \\
\hline 12. & Kecermatan petugas dalam melayani pelanggan & 379,3 & 596,5 & $-217,2$ & 17 \\
\hline 13. & $\begin{array}{l}\text { Petugas merespon setiap pelanggan/pemohon yang ingin } \\
\text { mendapatkan pelayanan }\end{array}$ & 448,1 & 475,6 & $-27,5$ & 19 \\
\hline 14. & Petugas melakukan pelayanan dengan cepat dan tepat & 426,9 & 697 & $-270,1$ & 9 \\
\hline 15. & Petugas melakukan pelayanan dengan inisiatif dan cermat & 587,7 & 535,2 & 52,4 & 21 \\
\hline 16. & $\begin{array}{l}\text { Petugas membantu pelanggan memperoleh informasi dan } \\
\text { merespon keluhan pelanggan }\end{array}$ & 220,9 & 499,7 & $-278,8$ & 7 \\
\hline 17. & $\begin{array}{l}\text { Petugas dapat mengantisipasi dan memahami kebutuhan } \\
\text { khusus pelanggan }\end{array}$ & 448,1 & 724,18 & -276 & 8 \\
\hline 18. & Jaminan kemudahan prosedur pelayanan & 533,7 & 227,4 & 306,2 & 24 \\
\hline 19. & Jaminan kemudahan persyaratan pelayanan & 426,9 & 131,7 & 295,1 & 22 \\
\hline 20. & Jaminan kepastian biaya dalam pelayanan & 367,7 & 575,8 & -208 & 18 \\
\hline 21. & Jaminan kepastian waktu penyelesaian pelayanan & 256,5 & 697 & $-440,5$ & 1 \\
\hline 22. & Petugas melayani dengan sikap ramah & 424,9 & 691,1 & $-266,2$ & 10 \\
\hline 23. & Petugas melayani dengan sikap sopan santun & 426,9 & 684 & $-257,1$ & 13 \\
\hline 24. & $\begin{array}{l}\text { Petugas melayani dengan tidak diskriminatif (membeda- } \\
\text { bedakan) }\end{array}$ & 420,5 & 684 & $-263,5$ & 11 \\
\hline 25. & Petugas melayani dan menghargai setiap pelanggan & 587,7 & 610,2 & $-22,5$ & 20 \\
\hline 26. & Petugas mendahulukan kepentingan pemohon/pelanggan & 403,7 & 664,6 & $-260,9$ & 12 \\
\hline
\end{tabular}

Berdasarkan hasil perhitungan Tabel 4, dapat diketahui bahwa nilai gap yang terjadi pada masingmasing kriteria memiliki nilai gap positif dan negative, yang berarti nilai gap positif menunjukkan masyarakat pengguna layanan E-KTP pada DISPENDUKCAPIL Kabupaten Gresik merasa puas terhadap pelayanan yang diterima. Selain itu, dapat diketahui nilai gap positif tertinggi yaitu pada kriteria "penampilan petugas/aparatur dalam melayani pelanggan" sebesar 413,0795 menunjukkan bahwa masyarakat pengguna layanan E-KTP pada DISPENDUKCAPIL Kabupaten Gresik merasa puas sehingga perlu untuk dipertahankan. Gap yang bernilai negatif menunjukkan bahwa masyarakat pengguna layanan E-KTP pada DISPENDUKCAPIL Kabupaten Gresik merasa tidak puas terhadap 
pelayanan yang diterima, dapat dilihat pada Tabel 3 nilai gap negatif terbesar yaitu pada kriteria "jaminan kepastian waktu penyelesaian pelayanan" yaitu sebesar -440,52 menunjukkan bahwa perlu diperhatikan dan adanya perbaikan.

\section{c. Perancangan Blueprint Perbaikan dan Rekomendasi}

Hasil perhitungan gap SERVQUAL menunjukkan lima kriteria dengan nilai gap tertinggi yaitu jaminan kepastian waktu, kenyamanan tempat melakukan pelayanan, tempat parkir yang luas, penggunaan media alat bantu pelayanan dan kemudahan memperoleh akses layanan. Berdasarkan permasalahan tersebut, dapat diberikan beberapa saran perbaikan sebagai berikut:

1) Jaminan kepastian waktu penyelesaian pelayanan

a. Mendata permasalahan yang menghambat proses pembuatan E-KTP untuk memonitor sehingga dapat meminimalisir hambatan yang ada.

b. Mendata permasalahan pelanggan yang mengurus ulang E-KTP karena data ganda dan data anomali untuk memonitor berapa banyak data ganda dan anomali yang telah diurus setiap harinya.

c. Memberikan surat panggilan untuk masyarakat yang memiliki data ganda atau data anomali untuk segera diurus karena membutuhkan proses waktu yang lama.

d. Memperbaiki sistem server agar tidak terjadi trouble yang menghambat pelayanan.

2) Kenyamanan tempat melakukan pelayanan

a. Menyediakan ruang smoking area agar pelanggan yang menunggu dikursi tunggu luar ruangan pelayanan E-KTP merasa nyaman bebas asap rokok.

b. Menambah kursi tunggu pelanggan.

c. Menyediakan rak berisi koran atau majalah sehingga pelanggan menunggu antrian tidak jenuh.

d. Memajang papan informasi untuk mengedukasi masyarakat mengenai "dr.Kepo" (dokter kependudukan online adalah aplikasi yang digunakan untuk mengetahui diagnose penyakit registrasi kependudukan, mengambil resep dan mengobatinya secara mobile dari smartphone serta memanfaatkan layanan pendaftaran administrasi kependudukan secara online) dan program-program yang dilakukan DISPENDUKCAPIL Kabupaten Gresik seperti "KAKEKKU DATANG" (Kartu Keluargaku Data Ulang).

3) Tempat parkir yang luas

a. Kebijakan parkir gratis untuk parkir di dalam kantor DISPENDUKCAPIL Kabupaten Gresik, memberikan papan tulisan parkir gratis dan memberikan karcis parkir.

b. Mengajukan perluasan kantor DISPENDUKCAPIL Kabupaten Gresik karena merupakan kantor pelayanan publik yang diakses oleh masyarakat sehingga membutuhkan lahan yang luas.

4) Penggunaan media alat bantu pelayanan (misalnya: mesin nomor antrian, speaker panggilan pelanggan).

a. Pengadaan mesin nomor antrian, layar monitor nomor antrian untuk di dalam ruang E-KTP, dan speaker panggilan nomor antrian untuk di dalam ruang E-KTP dan di luar ruang E-KTP.

b. Penambahan alat rekam sidik jari dan kornea mata.

c. Penambahan mesin cetak E-KTP.

5) Kemudahan memperoleh akses layanan

a. Menambah loket cetak E-KTP dibeberapa kecamatan.

b. Mengedukasikan sistem online yang ditetapkan seperti layanan online "dr.Kepo" yang dapat mempermudah masyarakat untuk mengakses layanan DISPENDUKCAPIL Kabupaten Gresik.

Beberapa saran perbaikan yang diberikan dimasukkan kedalam komponen blueprint jasa, yang dapat dilihat pada Gambar 4 dan Gambar 5. Untuk komponen physical evidence yaitu karcis parkir resmi untuk mempermudah petugas parkir dalam mengawasi kendaraan yang masuk dan keluar, papan 
keterangan parkir gratis agar kebijakan yang diberikan DISPENDUKCAPIL Kabupaten Gresik jelas tanpa memungut retribusi, smoking area digunakan untuk pelanggan yang sedang merokok tanpa mengganggu pelanggan lain yang sedang menunggu dikursi tunggu luar ruangan E-KTP, akrilik display poster digunakan untuk menambah estetika ruang pelayanan E-KTP agar tidak monoton sekaligus mengedukasi pelanggan mengenai program "KAKEKKU DATANG" maupun "dr.Kepo" agar pelanggan lebih sadar akan program-program ataupun informasi yang dilakukan oleh DISPENDUKCAPIL Kabupaten Gresik, dan rak koran serta majalah disediakan untuk pelanggan agar tidak bosan ketika menunggu antrian. Untuk komponen support process yaitu mesin nomor antrian, layar monitor antrian dan speaker nomor antrian digunakan untuk mengelola aliran pelanggan, mengurangi kesalahan urutan nomor antrian, dan memudahkan petugas nomor antrian untuk fokus pada pelayanan informasi dan pengecekkan berkas. Speaker nomor antrian dipasang tidak hanya di dalam ruang layanan E-KTP saja tetapi juga dipasang di luar ruang layanan E-KTP untuk memudahkan pelanggan yang menunggu dikursi tunggu luar mengetahui nomor antrian yang akan dilayani. Untuk blueprint jasa terdapat beberapa aktivitas yang diberi tanda " $\mathrm{F}$ " (possibility failed) yang menunjukkan bahwa aktivitas tersebut rentan terjadi kesalahan akibat human error ataupun machine error. Hal ini terjadi karena benda elektronik seperti mesin, layar monitor, speaker membutuhkan maintenance sehingga masih ada potensi untuk terjadi error.

Untuk pengadaan alat rekam sidik jari, alat rekam kornea mata, dan mesin cetak E-KTP, DISPENDUKCAPIL Kabupaten Gresik dapat melakukan pengadaan sesuai budget yang telah ditentukan pemerintah karena pengadaan alat tersebut telah diatur khusus dalam konsorsium yang merupakan gabungan dari beberapa perusahaan yang berbeda untuk membantu mengimplementasikan program Nasional E-KTP.

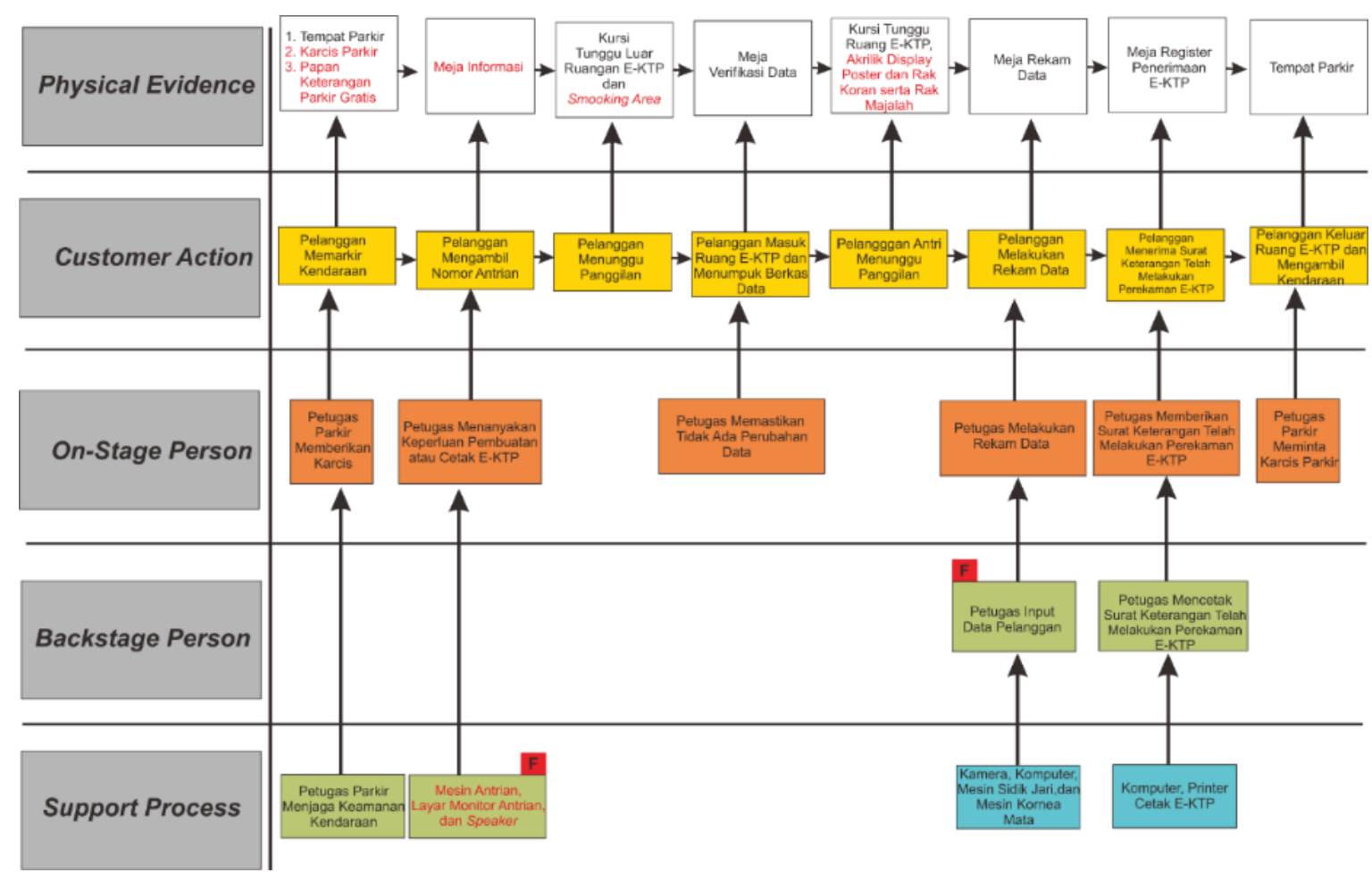

Gambar 4. Blueprint Perbaikan Layanan Pembuatan Awal E-KTP 


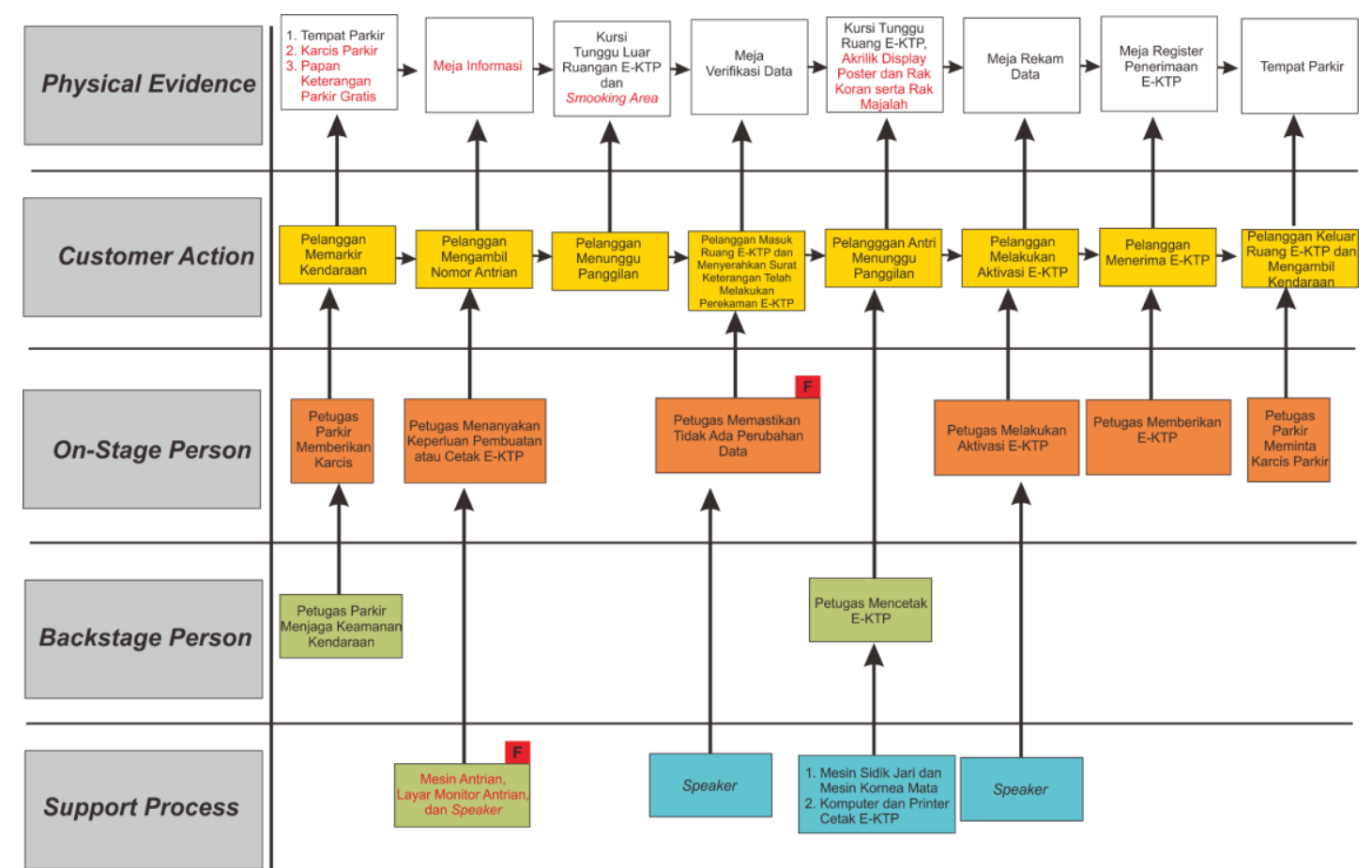

Gambar 5. Blueprint Perbaikan Layanan Cetak E-KTP

\section{Kesimpulan}

Berdasarkan hasil penelitian, diketahui bahwa pada kualitas pelayanan DISPENDUKCAPIL Kabupaten Gresik memiliki enam kriteria yang memiliki gap bernilai positif yang artinya pelanggan merasa puas dan dua puluh kriteria yang memiliki nilai gap negatif, atau 76,9\% kriteria dengan gap negative yang artinya pelanggan merasa belum puas terhadap pelayanan yang diberikan oleh DISPENDUKCAPIL Kabupaten Gresik sehingga perlu adanya perbaikan. Rekomendasi perbaikan diutamakan pada 5 kriteria yang memiliki gap tertinggi, yaitu jaminan kepastian waktu pelayanan, kenyamanan tempat pelayanan, tempat parkir yang luas, penggunaan media alat bantu pelayanan, dan kemudahan memperoleh akses layanan. Diharapkan, hasil penelitian ini dapat diimplementasikan oleh DISPENDUKCAPIL Kabupaten Gresik agar kualitas pelayanannya dapat ditingkatkan. Selain itu, penelitian selanjutnya diharapkan dapat dilakukan pada aspek pekerjaan lain selain pelayanan E-KTP, agar pengukuran kualitas pelayanan DISPENDUKCAPIL Kabupaten Gresik dapat dilakukan secara menyeluruh.

\section{Daftar Pustaka}

Carr, D. K., dan Littman, I. D. (1990). Excellence in government: Total quality management in the 1990s. New York, NY: Coopers \& Lybrand.

Falch, L., dan de Silva, S.W. (2018). Fuzzy techniques to reduce subjectivity and combine qualitative and quantitative criteria in a multi-objective design problem. IEEE 9th Annual Information Technology, Electronics and Mobile Communication Conference (IEMCON), Vancouver, BC, 2018, pp. 42-48.

Ghozali, I. (2016). Aplikasi Analisis Multivariete dengan Program IMB SPSS 23. Semarang: Badan Penerbit Universitas Diponegoro.

Mwita, J. I. (2000). Performance Management Model: A system-based approach to public service quality. International Journal of Public Sector Management, 13(1), 19-37.

Parasuraman, A., Zeithmal, V., dan Berry, L. (1985). A conceptual model of service quality and its implication for future research. Journal of Marketing, 49(4), 41-50. 
Pyon, C. U., Lee, M. J., dan Park, S. C. (2009). Decision support system for service quality management using customer knowledge in public service organization. Expert System with Application, 36, 8227-8238.

Sugiyono. (2017). Metode Penelitian Kuantitatif, Kualitatif dan R\&D. Bandung: Alfabeta.

Umar, H. (2002). Metodologi Penelitian, untuk Skripsi dan Tesis Bisnis. Jakarta: PT. Gramedia Pustaka Utama.

Yang, D.-H., Kim, S., Nam, C., dan Lee, L.-G. (2004). The future of e-government: Collaboration across citizen, business and government, Electronic Government: third international conference proceedings, 558-559.

Zoraghi, N., Amiri, M., Talebi, G. et al. (2013). A fuzzy MCDM model with objective and subjective weights for evaluating service quality in hotel industries. Journal of Industrial Engineering International, 9(38). 